\title{
Duration of postpartum estrus in the prairie vole
}

\author{
JOYCE E. HOFMANN \\ Illinois Natural History Survey, Champaign, Illinois \\ and \\ LOWELL L. GETZ \\ University of Illinois, Urbana, Illinois
}

\begin{abstract}
The present study was designed to delineate the duration of postpartum estrus in the prairie vole, Microtus ochrogaster. Breeding pairs were separated prior to parturition, and males were reintroduced to the females $0-12 \mathrm{~h}, 12-24 \mathrm{~h}, 24-48 \mathrm{~h}$, or $48-72 \mathrm{~h}$ postpartum. Pairs were observed for $1 \mathrm{~h}$ to determine whether mating occurred. Eighty percent of females in the first two time intervals were receptive within $24 \mathrm{~h}$ of parturition, $60 \%$ of females in the third time interval mated with males $24-48 \mathrm{~h}$ postpartum, and only $10 \%$ of females in the final time interval mated 48-72 $\mathrm{h}$ following parturition. These results indicate that postpartum estrus in this species typically lasts only $24-48 \mathrm{~h}$.
\end{abstract}

A postpartum estrus is apparently characteristic of microtine rodents, but the duration has not been determined for many species (Hasler, 1975). Richmond and Conaway $(1969 a, 1969 b)$ reported that female prairie voles, Microtus ochrogaster, typically remained in postpartum estrus (as determined from vaginal smears of isolated females) for 1-4 days following parturition, although 1 female remained in estrus for 6 days. Incidental observations during the course of behavioral experiments with animals from our laboratory colony indicated that females of this species might remain in postpartum estrus for a very brief period. Therefore, we conducted a study to define more precisely the duration of postpartum estrus in prairie voles. Behavioral receptivity of the females was used as the indicator of estrus.

\section{METHOD}

Laboratory-reared pairs that had produced at least two litters were used in this study. The pairs were maintained in $25 \times 40 \mathrm{~cm}$ plastic breeding cages with wood-chip bedding; Purina Rabbit Chow and water were provided ad lib. The animals were housed in a temperature-controlled room $\left(24^{\circ} \mathrm{C}\right)$ with a $15-\mathrm{h}: 9$-h light-dark cycle.

The male and offspring of a pair were removed from the cage 18 days after the birth of a litter. The female's cage was checked for neonates daily at approximately 0800,1500 , and $2200 \mathrm{~h}$. Following parturition, the mate was reintroduced into the cage with the female and the neonates during one of the following time intervals: $0-12 \mathrm{~h}, 12-24 \mathrm{~h}$, 24-48 $\mathrm{h}$ or 48-72 $\mathrm{h}$ postpartum (based on the estimated time of birth). The pair was observed for $1 \mathrm{~h}$ to determine whether the female was receptive and mating occurred. If the pair mated, the female was considered to have been in estrus. Ten different females were tested for each of the four time intervals.

This research was supported by NSF Grant No. DEB 78-25864 and NIH Grant No. HD 09328 to L. L. Getz. We thank Leah Gavish and Kathryn R. Gubista for their invaluable assistance. Requests for reprints should be sent to Lowell L. Getz, Department of Ecology, Ethology, and Evolution, University of Illinois, $505 \mathrm{~S}$. Goodwin, Urbana, IL 61801 .

\section{RESULTS AND DISCUSSION}

Eight of 10 females mated within $12 \mathrm{~h}$ of parturition; 8 of 10 females mated $12-24$ h following parturition; 6 of 10 females mated $24-48 \mathrm{~h}$ postpartum; but only 1 of 10 mated 48-72 $\mathrm{h}$ postpartum. The proportions of females that mated within $24 \mathrm{~h}$ and 24-72 $\mathrm{h}$ following parturition were significantly different $\left[\chi^{2}(1)=10.0, p<.005\right]$. It appears that most female prairie voles remain in postpartum estrus for approximately $24 \mathrm{~h}$ if not mated. After $24 \mathrm{~h}$, they are less likely to be in estrus, and very few females remain in estrus beyond $48 \mathrm{~h}$ following parturition. These results confirm, and further delineate, those of Richmond and Conaway (1969a, 1969b) in indicating a short duration for postpartum estrus.

However, intervals between litters considerably longer than the normal gestation period are known to occur occasionally among breeding pairs of prairie voles; this may be an indication that postpartum estrus may be prolonged under some conditions. Richmond and Conaway (1969a) noted litter intervals of up to 63 days; litter intervals occurred with a minor peak at 34-43 days, but $61.5 \%$ ranged from 21 to 23 days (the normal gestation period). Of 233 litter intervals of known length in our laboratory colony, $90.5 \%$ were $21-23$ days and only $5.2 \%$ were longer than 25 days.

A short period of postpartum estrus is consistent with the monogamous mating system displayed by the prairie vole (Getz, Carter, \& Gavish, 1981; Getz \& Hofmann, 1986). The male and female of a pair cohabit in a nest and have been found together in the nest approximately $40 \%$ of the time (Gruder-Adams \& Getz, 1985; Hofmann, Getz, \& Gavish, 1984). Radiotracked males were in the nest an average of $48 \%$ of the time (Hofmann et al., 1984); males leave the nest to forage every 3-4 h (Getz, unpublished data). If a male was not in the nest at the time the female gave birth, he could be expected to return 
within 2-3 $\mathrm{h}$. If a male did not return to the nest within $24 \mathrm{~h}$, it would probably indicate that he had been taken by a predator or had dispersed. Under such social conditions, a postpartum estrus of $24-48 \mathrm{~h}$ would be adequate to ensure successful mating of most females.

\section{REFERENCES}

Getz, L. L., CARTer, C. S., \& GAvish, L. (1981). The mating system of the prairie vole, Microtus ochrogaster: Field and laboratory evidence for pair-bonding. Behavioural Ecology \& Sociobiology, 8, 189-194.

Getz, L. L., \& HofmanN, J. E. (1986). Social organization in freeliving prairie voles, Microtus ochrogaster. Behavioural Ecology and Sociobiology, 18, 275-282.

Gruder-Adams, S., \& GeTZ, L. L. (1985). Comparison of the mating system and paternal behavior in Microtus ochrogaster and M. pennsylvanicus. Journal of Mammalogy, 66, 165-167.

HASLER, J. F. (1975). A review of reproduction and sexual maturation in the microtine rodents. The Biologist, 57, 52-86.

HofmanN, J. E., GeTZ, L. L., \& GAvish, L. (1984). Home range overlap and nest cohabitation of male and female prairie voles. American Midland Naturalist, 112, 314-319.

Richmond, M. E., \& ConaWAY, C. H. (1969a). Induced ovulation and oestrus in Microtus ochrogaster. Journal of Reproduction \& Fertility, Supplement, 6, 357-376.

Richmond, M. E., \& Conaway, C. H. (1969b). Management, breeding, and reproductive performance of the prairie vole, Microtus ochrogaster, in a laboratory colony. Laboratory Animal Care, 19, 80-87.

(Manuscript received for publication March 13, 1986.) 